\title{
Recent glacier mass changes in the Gulf of Alaska region from GRACE mascon solutions
}

\author{
Scott B. LUTHCKE, ${ }^{1}$ Anthony A. ARENDT, ${ }^{2}$ David D. ROWLANDS, ${ }^{1}$ \\ John J. MCCARTHY, ${ }^{3}$ Christopher F. LARSEN ${ }^{4}$ \\ ${ }^{1}$ Planetary Geodynamics Laboratory, Code 698, NASA Goddard Space Flight Center, Greenbelt, Maryland 20771, USA \\ E-mail: Scott.B.Luthcke@nasa.gov \\ ${ }^{2}$ Cryospheric Sciences Branch, Code 614.1, NASA Goddard Space Flight Center, Greenbelt, Maryland 20771, USA \\ ${ }^{3}$ SGT Inc., 7701 Greenbelt Road, Suite 400, Greenbelt, Maryland 20770, USA \\ ${ }^{4}$ Geophysical Institute, University of Alaska, 903 Koyukuk Drive, Fairbanks, Alaska 99775-7320, USA
}

\begin{abstract}
The mass changes of the Gulf of Alaska (GoA) glaciers are computed from the Gravity Recovery and Climate Experiment (GRACE) inter-satellite range-rate data for the period April 2003September 2007. Through the application of unique processing techniques and a surface mass concentration (mascon) parameterization, the mass variations in the GoA glacier regions have been estimated at high temporal $(10$ day) and spatial $(2 \times 2$ arc-degrees) resolution. The mascon solutions are directly estimated from a reduction of the GRACE K-band inter-satellite range-rate data and, unlike previous GRACE solutions for the GoA glaciers, do not exhibit contamination by leakage from mass change occurring outside the region of interest. The mascon solutions reveal considerable temporal and spatial variation within the GoA glacier region, with the largest negative mass balances observed in the St Elias Mountains including the Yakutat and Glacier Bay regions. The most rapid losses occurred during the 2004 melt season due to record temperatures in Alaska during that year. The total mass balance of the GoA glacier region was $-84 \pm 5 \mathrm{Gta}^{-1}$ contributing $0.23 \pm 0.01 \mathrm{~mm} \mathrm{a}^{-1}$ to global sea-level rise from April 2003 through March 2007. Highlighting the large seasonal and interannual variability of the GoA glaciers, the rate determined over the period April 2003-March 2006 is $-102 \pm 5 \mathrm{Gt} \mathrm{a}^{-1}$, which includes the anomalously high temperatures of 2004 and does not include the large 2007 winter balance-year snowfall. The mascon solutions agree well with regional patterns of glacier mass loss determined from aircraft altimetry and in situ measurements.
\end{abstract}

\section{INTRODUCTION}

The world's ice sheets, ice caps and glaciers are garnering much attention because of their sensitivity to climate change and their contributions to global sea-level rise (GSLR) (Alley and others, 2005; Cazenave, 2006). While considerable focus has been placed on quantifying the mass balance of the Greenland and Antarctic ice sheets, due to their large ice volume and potential contribution to GSLR, mountain glaciers and ice caps presently contribute more to GSLR than the ice sheets combined (Meier and others, 2007). Existing measurements indicate that the largest share of the mass losses from mountain glaciers and ice caps comes from those located in maritime, coastal environments (Dyurgerov and McCabe, 2006), attributable to the high mass turnover and sensitivity of these glaciers to climate variations (Meier, 1984) and the potential for rapid mass losses through tidewater glacier dynamics (Meier and Post, 1987; O'Neel and others, 2005). Although the total sea-level rise potential from mountain glaciers is small relative to the ice sheets, mountain glaciers will likely dominate the cryospheric sealevel budget during the next 50-100years (Meehl and others, 2007; Meier and others, 2007). The subpolar glaciers in Alaska and northwestern Canada, bordering the Gulf of Alaska, (GoA glaciers) are the largest known contributors to GSLR of all mountain glacier systems, showing significant accelerated ice loss and wastage accounting for $\sim 15 \%$ of the present-day eustatic component of GSLR (Meier and others, 2007).
Ground measurements providing long-term time series of seasonal mass balance are sparse due to the remote and inaccessible nature of most land-ice regions. The few existing GoA benchmark glacier observations yield valuable information on seasonal variability of glacier mass balances, but do not well represent large and dynamic glaciers that dominate the contribution to GSLR (Arendt and others, 2002). Airborne laser altimetry has greatly expanded the spatial coverage of measurements over a wide range of GoA glacier types. Repeat surveys along the same flight path of an earlier profile, or comparison of a survey with historical maps, yield changes in elevation that are extrapolated to individual glaciers or entire glacier regions (Echelmeyer and others, 1996; Arendt and others, 2002). Regional estimates of glacier mass balance from aircraft altimetry have two primary sources of error: (1) Glacier mass balance is not only a function of regional climate, but also of glacier dynamics, which is highly variable and glacier-specific (Arendt and others, 2006), requiring direct sampling of tidewater and lake-calving glaciers that are making disproportionate contributions to regional mass changes (Larsen and others, 2007). (2) Altimetry studies rely on assumptions about ice density in converting volume to mass changes, and nearsurface densities can be highly variable, especially over short periods. Although altimetry studies provide broad regional coverage, they lack detailed temporal information.

For several decades, geodesists have used the concept of satellite-to-satellite tracking to study the gravitational potential from changes in inter-satellite range and velocity 
(e.g. Rummel, 1980; Kahn and others, 1982; Gaposchkin, 2000; Rowlands and others, 2002). However, direct measurements of surface mass change at spatial scales less than $400 \mathrm{~km}$ with 10 day resolution were not possible before the use of the data acquired by the NASA/DLR (German Aerospace Research Center) Gravity Recovery and Climate Experiment (GRACE) mission (Rowlands and others, 2005; Luthcke and others, 2006b). Since its launch in March 2002, GRACE has been acquiring ultra-precise $\left(0.1 \mu \mathrm{m} \mathrm{s}^{-1}\right)$ intersatellite K-band range and range-rate (KBRR) measurements taken between two satellites in polar orbit approximately $200 \mathrm{~km}$ apart (Tapley and others, 2004). The changes in range rate sensed between the GRACE satellites provide a mapping of static and time-variable gravity.

Here we estimate mass variations of the GoA glacier region at 10 day temporal and $2 \times 2$ arc-degrees $\left(\sim 49000 \mathrm{~km}^{2}\right)$ spatial sampling through unique processing of the GRACE level-1 data and a parameterization of local mass variations as surface mass concentrations (mascons) (Muller and Sjogren, 1968; Rowlands and others, 2005; Luthcke and others, 2006b). We investigate the impact of atmosphere, ocean, tides, terrestrial water storage (TWS) and glacial isostatic adjustment (GIA) forward modeling on our massvariation time series. Unlike previous studies that investigate TWS and GIA effects through comparisons with the monthly spherical harmonic fields after the reduction of the KBRR data, we forward-model these mass-variation components as part of the level-1 data processing and formal reduction of the KBRR data. Therefore, the performance of the forward models is quantitatively measured through the change in KBRR residuals and resultant mascon solutions. Furthermore, we show that the mascon solutions isolate the mass variation within each mascon region, significantly reducing leakage from outside regions. We present the details of the highresolution mascon solution technique applied here, an error analysis and a discussion of the results including comparisons to independent data for the purposes of validation.

\section{DETERMINING GLACIER MASS VARIATON FROM GRACE: METHODS}

\section{Previous studies: regional averaging of monthly spherical harmonic fields}

To investigate surface mass variations, the GRACE project provides monthly global spherical harmonic gravity fields estimated from the processing of the mission level-1 data (Tapley and others, 2004). This processing involves the reduction of the inter-satellite KBRR data with precise positioning, attitude and accelerometer data to isolate gravity forces from non-conservative surface forces (Tapley and others, 2004; Luthcke and others 2006a). The monthly global spherical harmonic gravity fields, in the form of Stokes coefficients, are formally estimated in a weighted leastsquares minimization of the KBRR residuals (difference between the observations and a computed observation based on the initial estimates of the gravity fields and forward models) (Luthcke and others, 2006a). The error in surface mass estimates derived from these monthly spherical harmonic fields greatly increases as the spatial wavelength of interest gets smaller, requiring spatial smoothing and regional averaging of mass variation (Swenson and Wahr, 2002; Howarth and Dietrich, 2006). In addition, the monthly spherical harmonic Stokes coefficients have significant errors at the orbit resonant orders 15 and 16 causing spatial 'striping' error (Luthcke and others, 2006a), further requiring spatial smoothing and averaging.

Smoothing and regional averaging techniques have recently been used to estimate overall glacier mass balance for the GoA region from the GRACE monthly spherical harmonic fields (Tamisiea and others, 2005; Chen and others, 2006). While these studies represent an important advance in using space-borne gravity measurements to assess glacier mass balance, they are limited in their temporal (monthly) and spatial (800-1000 km) resolution. These studies employ long-wavelength smoothing and averaging compared to the glacier signal source dimension; therefore, they must account for signal attenuation and leakage of signal out of the region, as well as leakage into the region from outside sources such as TWS and GIA. Tamisiea and others (2005) used a scaling relationship of increasing annual mass variation as a function of decreasing smoothing radii to extrapolate the annual variation and rate for the GoA region's ice variation. Chen and others (2006) minimized spatial noise by applying a two-step smoothing technique, and attempted to account for attenuation and leakage by matching numerically simulated mass change to that obtained from the smoothed GRACE monthly fields. Rangelova and Sideris (in press) have modeled North American geoid rates using a more advanced spherical harmonic analysis approach that may better avoid leakage using the method of principal component/empirical orthogonal functions. Still, these methods do not formally minimize the discrepancies between the GRACE intersatellite ranging observations and the computed observation signals derived from the estimates of surface mass variation. In addition to the limited spatial and temporal resolution of the results, these studies employed smoothing, numerical simulations and leakage investigations that do not use the GRACE KBRR observations; the fundamental observations of the GRACE mission are not being used as the objective criteria of performance.

\section{Mascon solutions}

Examination of the GRACE KBRR observations reveals coherent mass-variation signals at better than $400 \mathrm{~km}$ full wavelength spatial and 10 day temporal resolution at the mid-latitudes, and still better resolution at high latitudes (Rowlands and others, 2005). In this study we use the GRACE KBRR observations to estimate mass flux directly. This is accomplished by employing unique methods of processing the GRACE inter-satellite KBRR observations, along with the parameterization of local mass variations as surface mascons. The details of our GRACE data processing are discussed by Rowlands and others (2002) for the shortarc analysis and Luthcke and others (2006a) for the GRACE level-1 data processing (including accelerometer calibration). These processing techniques, combined with the mascon parameterization, have been used to estimate mass variation in the Amazon river basin (Rowlands and others, 2005) and Greenland ice-sheet drainage systems (Luthcke and others, 2006b). In this study, we further refine these techniques to formally estimate the mass variation of the GoA glacier regions through a direct reduction of the GRACE inter-satellite KBRR data.

The mean (over a specified period) gravitational potential of the Earth at any point on or above the surface of the Earth can be expressed in standard form as a spherical harmonic 
expansion (Hoffmann-Wellenhof and Moritz, 2005):

$$
\begin{aligned}
U(r, \vartheta, \lambda) \approx \frac{G M}{R}[ & \frac{R}{r} \bar{C}_{00}+\sum_{l=1}^{I_{\max }} \sum_{m=0}^{I}\left(\frac{R}{r}\right)^{I+1} \bar{P}_{l m}(\sin \vartheta) \\
& \left.\cdot\left(\bar{C}_{l m} \cos m \lambda+\bar{S}_{l m} \sin m \lambda\right)\right],
\end{aligned}
$$

where $r, \vartheta, \lambda$ are the spherical geocentric radius, latitude and longitude coordinates of the point where the geopotential is evaluated, $G M$ is the product of the universal gravitational constant and the Earth's mass, $R$ is the Earth's mean semimajor axis, $I, m$ are the spherical harmonic degree and order, $\bar{P}_{I m}$ are the fully normalized associated Legendre functions and $\bar{C}_{I m}, \bar{S}_{I m}$ are the fully normalized Stokes coefficients.

The formulation for mascon parameters is derived from the fact that a change in the gravitational potential caused by adding a small uniform layer of mass over a region at an epoch $t$ can be represented as a set of (differential) potential coefficients which can be added to the mean field. The delta coefficients can be computed (Chao and others, 1987):

$$
\begin{aligned}
\Delta \bar{C}_{I m}(t) & =\frac{\left(1+k_{l}^{\prime}\right) R^{2} \sigma(t)}{(2 I+1) M} \int \bar{P}_{I m}(\sin \vartheta) \cos m \lambda \mathrm{d} \Omega \\
\Delta \bar{S}_{I m}(t) & =\frac{\left(1+k_{l}^{\prime}\right) R^{2} \sigma(t)}{(2 I+1) M} \int \bar{P}_{I m}(\sin \vartheta) \sin m \lambda \mathrm{d} \Omega,
\end{aligned}
$$

where $k_{l}^{\prime}$ is the loading Love number of degree $l$, to account for the Earth's elastic yielding which in general counteracts the additional surface density, $\sigma(t)$ is the mass of the layer over a unit of surface area at the epoch $t$, and $\Omega$ is the solidangle surface area of the mascon region where $\sigma(t)$ is applied, $\mathrm{d} \Omega=\cos \vartheta \mathrm{d} \vartheta \mathrm{d} \lambda$.

For each mascon region, the above equation is used to generate a set of differential Stokes coefficients (complete to degree and order 60) that correspond to $1 \mathrm{~cm}$ of water over the region of interest. The estimated mascon parameter for each mascon region is a scale factor on the set of differential Stokes coefficients for that mascon region, giving a surface mass delta in equivalent centimeters of water. The solution is relative to the mean field and forward models of other geophysical processes of mass redistribution (e.g. atmosphere and ocean tides). The mascon parameters are estimated using least-squares differential correction, and therefore the change in KBRR observations per change in mascon parameters is needed for the estimation. The partial derivatives of the GRACE KBRR data with respect to the mascon parameters are computed as a dot product of the partials of the KBRR data with respect to standard Stokes coefficients and the differential Stokes coefficients computed from the equation above for the mascon region of interest:

$$
\frac{\partial O_{i}}{\partial P_{t}^{j}}=\sum_{l=1}^{I_{\max }} \sum_{m=0}^{I} \frac{\partial O_{i}}{\partial \bar{C}_{l m}} \cdot \Delta \bar{C}_{l m}^{j}+\frac{\partial O_{i}}{\partial \bar{S}_{l m}} \cdot \Delta \bar{S}_{I m^{\prime}}^{j}
$$

where $\partial O_{i} / \partial P_{t}^{j}$ is the partial derivative of the KBRR observation $i$ with respect to the $j$ mascon parameter $P^{j}$ at time $t$, and $\partial O_{i} / \partial \bar{C}_{I m}, \partial O_{i} / \partial \bar{S}_{I m}$ are the partial derivatives of the KBRR observations with respect to the geopotential Stokes coefficients. These partial derivatives are computed as part of the KBRR reduction and level-1 data processing. $\Delta \bar{C}_{I m^{\prime}}^{j} \Delta \bar{S}_{I m}^{j}$ are the delta Stokes coefficients for mascon region $j$.

\section{High-resolution mascons}

The mascon parameterization has been successfully applied to estimate mass variation of the Greenland ice sheet (GIS) at drainage-system spatial sampling and 10 day temporal sampling (Luthcke and others, 2006b). In this study we further advance this technique to estimate mass variation over $2 \times 2$ arc-degrees equal-area mascon regions $\left(\sim 49000 \mathrm{~km}^{2}\right)$, which are significantly smaller than the GIS drainage-system mascons previously used (Luthcke and others, 2006b). We term these high-resolution mascons (hi-res mascons) because the spatial resolution of these new mascons is significantly better than those in previous GRACE mascon studies (Rowlands and others, 2005; Luthcke and others 2006b). We define a series of mascons where the GoA glacier mascons (1-12), land mascons (13-103) and ocean mascons (104-262) are separately distinguished (Fig. 1). The mascons are directly estimated from short arc minimization of the GRACE KBRR data residuals exclusively within the local region of interest (Fig. 1a) (Rowlands and others, 2002, 2005; Luthcke and others, 2006a).

The GRACE KBRR and level-1 attitude and accelerometer data (including accelerometer calibration) are processed in daily arcs as outlined by Luthcke and others (2006a). In order to isolate ice-change signal, our mascon estimates are relative to models of both static and time-varying gravity. These time-varying gravity effects are forward-modeled in the daily arc reductions of the KBRR data (level- 1 data processing). Static mean gravity is modeled using the complete GGM02C GRACE gravity model through degree and order 150 (Tapley and others, 2004). We perform sensitivity analysis to assess the effects of differences in the forward modeling on our mascon solutions. Here we present the results using two very different forward models: v01 which is our simplest and least complete model; and v03 which represents our best forward modeling of the timevarying gravity. Our v01 forward modeling includes:

1. The ocean tides modeled according to GOTO0 (Ray 1999; Ray and Ponte, 2003), and

2. The atmospheric gravity modeled following Chao and $\mathrm{Au}$ (1991) using potential coefficients to degree and order 50 at 6 hour intervals derived from US National Centers for Environmental Prediction (NCEP) pressure grids (Petrov and Boy, 2004) assuming inverted barometer for the ocean response.

Our v03 forward modeling includes:

1. An updated ocean tide model, GOT4.7, with improvements in shallow waters and polar seas.

2. Atmospheric gravity modeled to degree and order 90 at 3 hour intervals derived from European Centre for Medium-Range Weather Forecasts (ECMWF) operational pressure grids.

3. Ocean mass gravity modeled using MOG2D, a barotropic ocean model forced by 6 hourly ECMWF pressure and winds (Carrre and Lyard, 2003), represented as potential coefficients to degree and order 90.

4. TWS modeled using the Global Land Data Assimilation System (GLDAS)/Noah $0.25^{\circ}, 3$ hour data represented as potential coefficients to degree and order 90 (Ek and others, 2003; Rodell and others, 2004). We have set the TWS contribution to zero for the major mountain glacier 

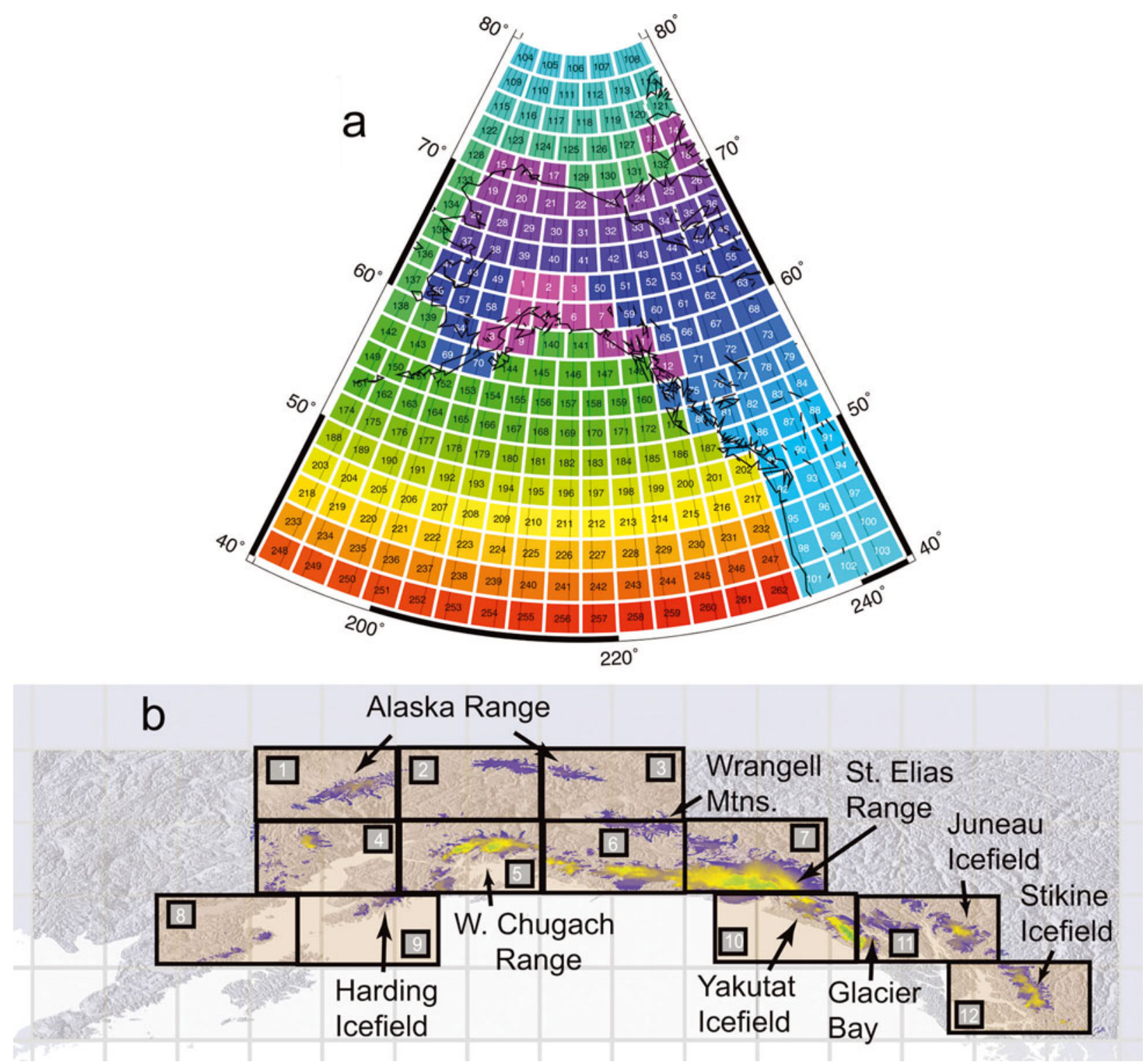

Fig. 1. (a) Alaska mascon definitions (approx. equal area $\sim 49000 \mathrm{~km}^{2}$ ). Mascons $1-12$ (magenta) represent the GoA glacier regions. (b) Detail of glacier region mascons 1-12.

areas of the globe using a $0.25^{\circ}$ mask (Raup and others, 2000) and have also zeroed the contribution for the Greenland and Antarctic ice sheets.

5. GIA is modeled using the ICE-5G (VM2) model and represented as potential coefficients to degree and order 90 (Peltier, 2004).

In addition to the forward models just discussed, we further correct our mascon solutions for the viscous component of post-Little Ice Age (LIA) GIA following the collapse of the Glacier Bay Icefield (Larsen and others, 2005). The regional post-LIA GIA model is rigidly constrained by approximately 100 precise GPS and relative sea-level (RSL) observations of uplift (Larsen and others, 2005). The magnitude of the postLIA GIA signal in the mascon glacier regions is $7 \mathrm{Gt} \mathrm{a}^{-1}$ with a $\pm 30 \%$ error estimated from the model comparisons to GPS vertical motions, raised shoreline records of RSL and tidegauge rates of RSL. Nearly all of the GIA forward-modeled signal in our GoA region of interest is attributed to the post-LIA GIA model. Still, the global ICE-5G (VM2) model is included for completeness to investigate the impact on our GoA glacier mascon solutions from signals outside our region of interest.

Figure $1 \mathrm{~b}$ shows the relationship between the GoA glacier mascons and the glacier-covered areas. In addition to the GoA glacier mascons, we estimate all surrounding local land and ocean mascons defined in Figure $1 \mathrm{a}$, as well as daily GRACE satellite baseline state orbital parameters to account for mass variations occurring outside our GoA glacier mascons of interest. The local solution exploits the fact that the signal from a mascon observed in GRACE KBRR data is centered over the mascon and is spatially limited in extent. The local solution technique minimizes contamination from the global propagation of errors outside the region of interest and takes advantage of the convergence of orbital tracks at high latitudes to improve spatial and temporal resolution over that of global solutions (Rowlands and others, 2005; Luthcke and others, 2006b).

Unlike global spherical harmonic solutions, local mascon solutions lend themselves to the application of both spatial and temporal constraint equations, which enable high 
spatial and temporal resolution. The spatial and temporal constraints are discussed in detail by Rowlands and others (2005) and summarized as applied to GIS mass estimates by Luthcke and others (2006b). The constraint equation is a simple exponential function of correlation time and distance, and induces pairs of estimated parameters located closely in time and or space to remain close in value. The correlation time and distance and the weight applied to scale the constraint relative to the data define the 'strength' which forces the pairs of parameters towards the same value. The use of these neighbor constraints in our mascon solutions provides a flexible trade-off between high resolution (more estimated parameters) and solution stability. These types of constraints have been used in many geophysical inverse problems, as well as, for example, in precise orbit determination (Luthcke and others, 2003).

For the solutions presented in this study, we group the ocean, land and GoA glacier mascons separately. Constraint equations are applied only between pairs of mascon parameters belonging to the same group, in order to isolate ice change from land and ocean. We use a correlation time of 10 days and a correlation distance of $200 \mathrm{~km}$, which is approximately one parameter sample in time and distance. We implement the scale of the constraint equations by weighting the data relative to the constraints. The optimal data weight is determined such that the mascon parameters that are one sample away from each other in both space and time have minor influence on each other. We have investigated the impact of the data weight (equivalent to the constraint scale) by performing solutions using data weights that are as much as five times smaller and larger than the optimal data weight, spanning more than an order of magnitude. We find that the impact on the estimated GoA mascon mass balance and annual amplitude is less than $5 \%$, while the $1 \sigma$ error estimates of the 10 day mascon solutions can change by as much as $50 \%$. Therefore, the constraints as applied here are important in reducing the error of the individual 10 day solutions, but have little impact on the underlying estimated ice-mass variation signal.

\section{ERROR ANALYSIS}

Using the methods discussed in the previous section, we estimate mass variation for each of the mascons in our local study region (Fig. 1) every 10 days from April 2003 through September 2007. The 10 day mascon solution $1 \sigma$ error estimates are obtained by calibrating the mascon leastsquares solution formal errors by the misfit of the mascon solutions and a 10 day width Gaussian filter (Luthcke and others, 2006b). To compute the total GoA region glacier mass-change time series, the individual glacier mascon time series are summed at each 10 day interval. The $1 \sigma$ errors associated with the total GoA glacier region are computed from the root-sum square (RSS) of the $1 \sigma$ formal errors of the GoA glacier mascons, and calibrated the same way as described above. The mascon time-series rate and annual amplitude are computed using a least-squares simultaneous estimation of a rate, annual, semi-annual and 161 day cycle (alias period of S2 tide error). Rates are computed using integer number of years to further avoid seasonal aliasing. The $1 \sigma$ error in the estimated rate is determined from the variance of the least-squares parameter considering a firstorder auto-regression structure for the mascon time series (Lee and Lund, 2004).

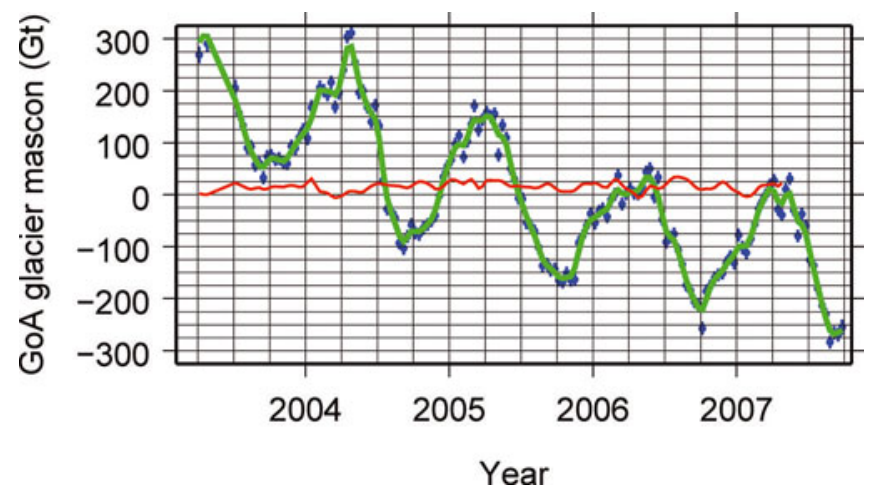

Fig. 2. Total GoA glacier mascon solution time series (cumulative net balance, April 2003-September 2007) computed from the sum of mascon region solutions 1-12 estimated from KBRR residual reduction using v01 forward modeling: 10 day estimates (blue dots with $1 \sigma$ error bars), Gaussian one-dimensional (1-D) filter with 10 day window applied to 10 day estimates (green curve), and difference between solutions estimated from KBRR residual reduction using v01 and v03 forward modeling (red curve).

Systematic errors in the GoA glacier mascon solutions due to atmospheric mass variation, ocean tides, ocean pressure and wind-driven mass variation, hydrology and GIA are investigated through the application of different forward models used in the KBRR reduction. We use the difference between the mascon solutions calculated from the v01 and v03 forward models as an estimate of systematic errors resulting from forward-modeling deficiencies. We find these potential systematic errors are well within our solution error bars and have little impact on the recovered signal. Post-LIA GIA modeling errors are difficult to quantify. However, we again note the magnitude of the post-LIA GIA signal in the mascon glacier regions is $7 \mathrm{Gta}^{-1}$ with a $\pm 2 \mathrm{Gta}^{-1}( \pm 30 \%)$ error estimated as discussed above.

\section{RESULTS AND DISCUSSION}

We present the results of our hi-res mascon solutions: the time series and trend of the total GoA glacier region mass variation (Fig. 2; Table 1), the time series and trends of individual glacier mascons (Fig. 3; Table 1), and the spatial distribution of mass trends for the entire solution domain (Fig. 4). Before investigating the trends and amplitudes of these results relative to previous glaciological studies, we analyze the sensitivity of our solutions to the forward models.

\section{Sensitivity to forward models}

The total GoA glacier region mass-variation time series computed from the sum of GoA glacier mascons 1-12 is shown in Figure 2. The time series is given for the period April 2003-September 2007 computed from the v01 forward modeling. The mascon solutions using the v03 forward modeling were computed from April 2003 through April 2007. The difference between the total glacier mascon solutions computed using the v01 and v03 forward modeling is shown as the red line in Figure 2. The comparison illustrates the negligible response of the glacier mascon solutions to differences in the forward modeling. Therefore, the systematic errors due to atmospheric and ocean tide mass-variation modeling are shown to be negligible inasmuch as our model difference represents the errors in 

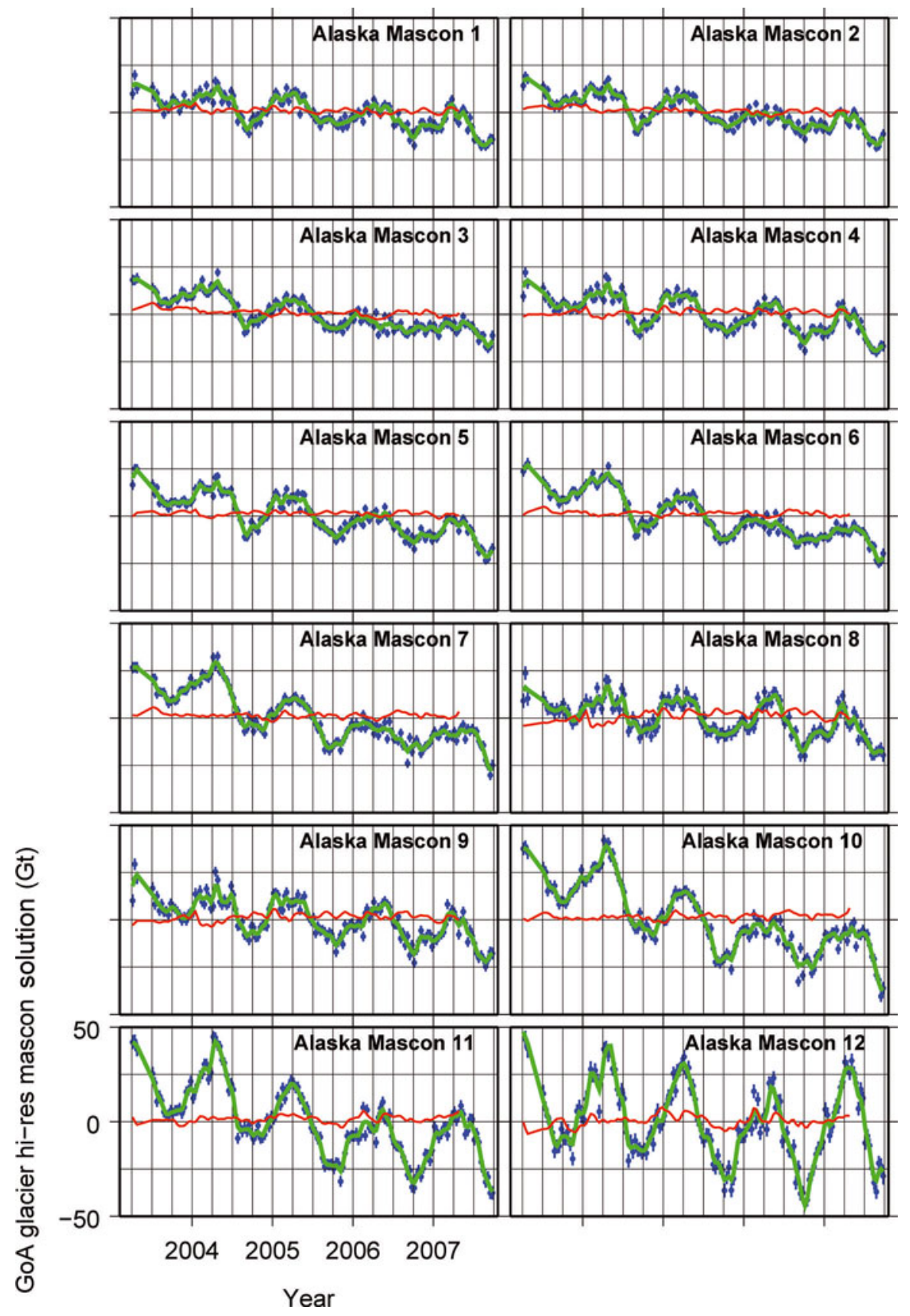

Fig. 3. GoA glacier hi-res mascon solution time series (cumulative net balance, April 2003-September 2007) estimated from KBRR residual reduction using v01 forward modeling: 10 day estimates (blue dots with $1 \sigma$ error bars), Gaussian 1-D filter with 10 day window applied to 10 day estimates (green curve), and difference between solutions estimated from KBRR residual reduction using v01 and v03 forward modeling (red curve).

these models. Leakage errors due to surrounding signals from ocean mass variation, GIA outside our region of interest (ICE-5G; Peltier, 2004) and hydrology are also shown to be negligible. This is in contrast to the study by Chen and others (2006) that found significant leakage effects from TWS and GIA using monthly spherical harmonic solutions and a regional averaging technique. Our results illustrate how the mascon technique can isolate the surface mass variations from a direct reduction of the GRACE KBRR observations, while regional averaging of the monthly spherical harmonic fields can spread and attenuate the mass signals, thus complicating the analysis of regional mass variation. Furthermore, we find the models comprising the v03 forward modeling represent a $12 \%$ reduction in the global KBRR residual variance (before estimation of timevariable gravity) and therefore are an improvement over the v01 models.

The spatial pattern of the hi-res mascon solution rates for the entire local solution area is displayed in Figure 4a. The largest mass losses are observed in the Yakutat and Glacier Bay region. The figure illustrates the significantly improved spatial resolution over that found in previous GRACE studies which exhibited substantial attenuation and spreading of signal throughout the land region and well into the GoA (Tamisiea and others, 2005; Chen and others, 2006). Figure $4 \mathrm{~b}$ presents the spatial distribution of the rates estimated from the v03 forward models. The signal is dominated by the TWS model (based on GLDAS/Noah) and 


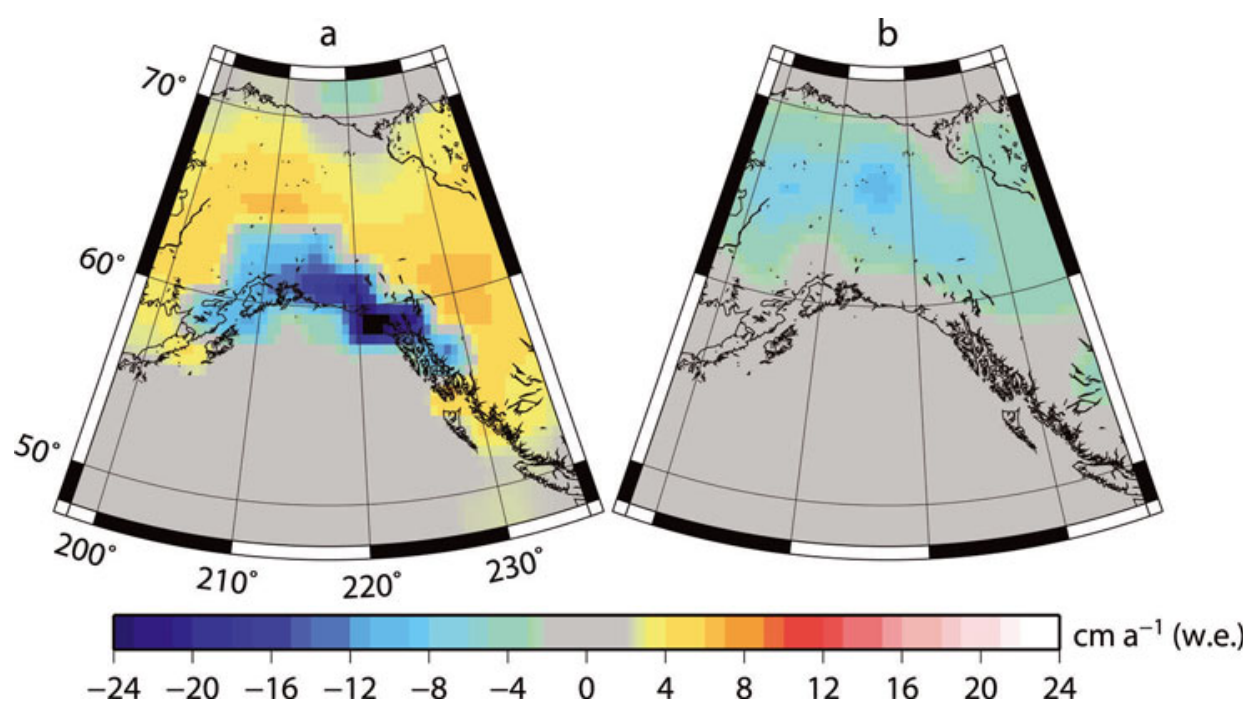

Fig. 4. (a) Spatial distribution of the hi-res mascon solution rates estimated from KBRR residual reduction using v03 forward modeling. The rates are recovered from the individual mascon time series through a simultaneous estimation of bias, rate, annual and semi-annual sinusoid. The rates have been corrected for post-LIA GIA. (b) Spatial distribution of v03 forward model rates. The signal is dominated by the GLDAS hydrology and accounts for much of the positive signal found in the mascon solution rates as seen in (a).

accounts for much of the positive signal found in the hi-res mascon solution rates as seen in Figure 4a. The results indicate the rates in the TWS forward model are inconsistent with the GRACE KBRR observations. The mascon solutions (determined directly from the GRACE KBRR observations) for the regions outside the GoA glacier mascons are approximately equal and opposite in sign to the TWS rates, and therefore are compensating for the mis-modeling in order to reduce the KBRR residuals. Much of the positive signal is near zero when performing solutions using the v01 forward modeling that does not include the TWS model. Fortunately, we have shown that the change in forward modeling has little impact on the GoA glacier mascon solutions (Figs 2 and 3). Therefore, the hi-res mascon solutions in this application appear not to suffer from signal leakage problems. While not a significant source of uncertainty for our hi-res mascon estimates of glacier mass balance, the potential error in the TWS rate may have significant ramifications for studies that rely on regional averaging of the harmonic fields and large corrections for TWS leakage.

\section{Mascon glacier mass-balance trends}

We interpret the mass trends in the GoA mascon solution time series (Figs 2 and 3; Table 1) as the regional glacier mass balance even though these regions contain both glaciated and non-glaciated areas. This assumes that all non-glacier sources of mass variation have been accounted for in our forward modeling, and that any snow falling on land surfaces outside the glacier regions melts completely in a given balance year (balance years begin in the fall of the previous calendar year).

Table 1. Summary statistics for GoA glacier mascons (v03 background modeling)

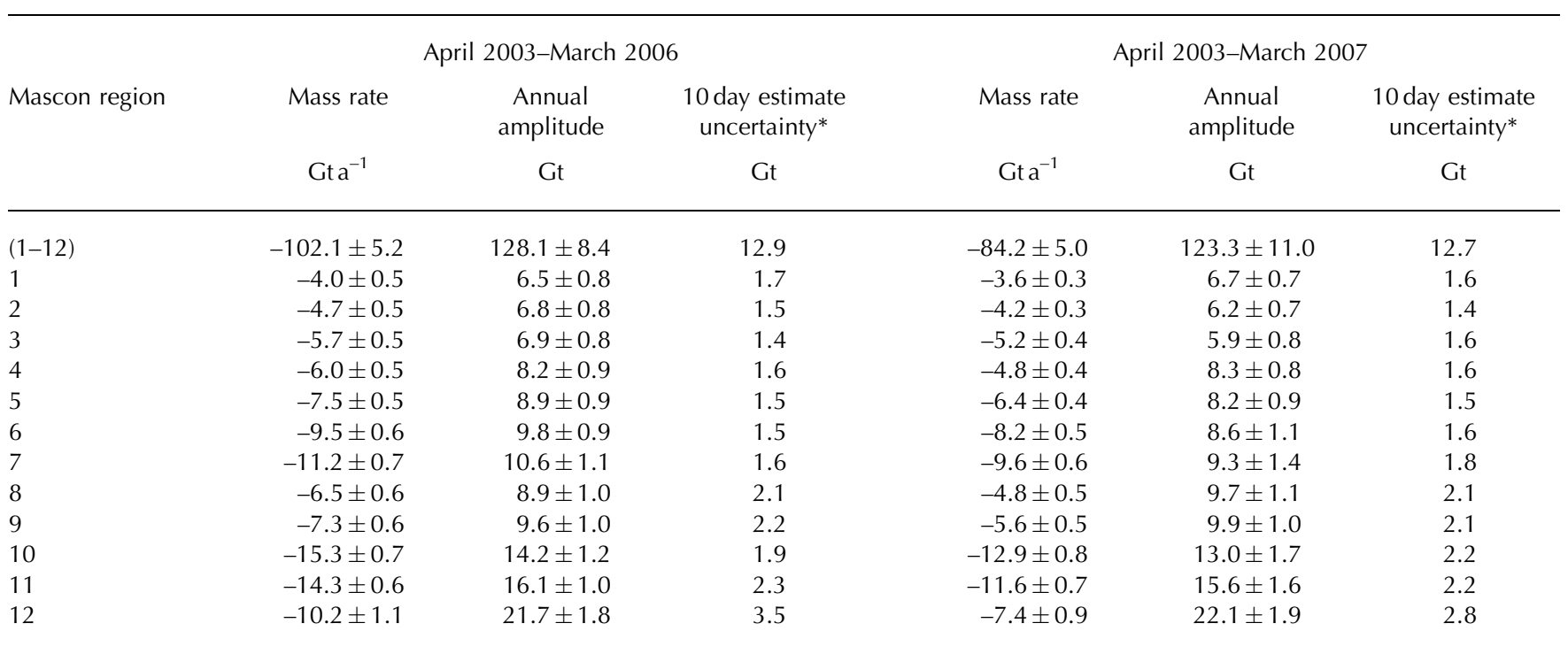

*Computed as std dev. of the difference between each 10 day solution and the 10 day Gaussian filter (see Figs 2 and 3 ). 
Table 2. Winter $\left(B_{\mathrm{W}}\right)$, summer $\left(B_{\mathrm{S}}\right)$ and net balances $(B)$, for the total GoA glacier mascon region between 2003 and 2007, determined as the difference between yearly maximum and minimum in the mascon time series (Fig. 2). Balance years begin in the fall of the previous calendar year

\begin{tabular}{lccc}
\hline Balance year & $B_{\mathrm{W}}( \pm 14)$ & $B_{\mathrm{S}}( \pm 14)$ & $B( \pm 20)$ \\
& $\mathrm{Gt}$ & $\mathrm{Gt}$ & $\mathrm{Gt}$ \\
\hline 2004 & 232 & -374 & -143 \\
2005 & 241 & -312 & -72 \\
2006 & 195 & -254 & -60 \\
2007 & 232 & -279 & -47 \\
\hline
\end{tabular}

The total GoA glacier region had a strongly negative mass balance that decreases in magnitude in the later part of the time series (Fig. 2), particularly for the fourth balance year, April 2006-March 2007. The mass balance averaged over the period April 2003-March 2007 is $-84.2 \pm 5.0 \mathrm{Gta}^{-1}$ (Table 1), contributing $0.23 \mathrm{~mm} \mathrm{a}^{-1}$ to GSLR. The sum of $2006 B_{\mathrm{s}}$ and $2007 B_{\mathrm{w}}$ is near zero (Table 2), corresponding with the unusually large snowfalls observed in the GoA region during the later part of 2006 and beginning of 2007 (Fig. 5). Excluding the fourth balance year with anomalously large snowfalls, the mass balance averaged over April 2003March 2006 is $-102.1 \pm 5.2 \mathrm{Gt} \mathrm{a}^{-1}$. This compares favorably with the $-96 \pm 35 \mathrm{Gta}^{-1}$ mass balance obtained from laser altimetry for the period from the mid-1990s to 2000/01 (Arendt and others, 2002). However, as we have seen in the mascon time series, there is significant interannual variability, so caution is necessary when comparing results from different periods.

Our mascon solution 3 year mass balance is in agreement with previous GRACE studies: $-110 \pm 30 \mathrm{Gta}^{-1}$ for the period June 2002-July 2004 (Tamisiea and others, 2005) and $-101 \pm 22 \mathrm{Gt} \mathrm{a}^{-1}$ for the period April 2002-November 2005 (Chen and others, 2006). However, from our analysis above, an underlying inference is that the rate in the GLDAS/Noah hydrology forward model is inconsistent with the GRACE KBRR observations. This would indicate that the massbalance estimates of Chen and others (2006) are actually not in agreement with our mascon 3 year mass balance, because the hydrology model accounted for a significant signal leakage correction $\left(-79 \mathrm{Gt} \mathrm{a}^{-1}\right)$ in the Chen and others (2006) analysis.

Large mass losses are observed in the southeast coastal glacier mascons 7, 10 and 11, representing the St Elias, Yakutat, Glacier Bay and Juneau Icefield regions (Fig. 3; Table 1). This is consistent with airborne laser-altimetry measurements that found the largest losses occurred in maritime regions containing numerous tidewater glaciers (Arendt and others, 2002). The Yakutat and Glacier Bay mascons 10 and 11 exhibit the largest mass loss, agreeing with Shuttle Radar Topography Mission (SRTM)-based measurements that found substantial ice-mass losses in this region from tidewater and lake-calving glaciers (Larsen and others, 2007). This region (in particular, Brady and Yakutat Glaciers) is susceptible to climate change because of the generally low elevation of the glaciers relative to their equilibrium-line altitudes (Larsen and others, 2007). The study found a Yakutat lake-calving glacier to have one of the largest volume losses of any glacier in the region (Larsen and others, 2007). It is important to note that the SRTM-based study compared SRTM data from 2000, covering $60^{\circ} \mathrm{N}$ and southward, with digital elevation model data from 1948, 1961 and 1984. The smallest rates of mass loss are found in the interior Alaska Range mascons 1-4 and mascon 8 in the far west of the GoA region containing little glaciated area.

A companion study has used concurrent aircraft laseraltimeter observations to validate the hi-res mascon solution estimates of glacier mass balance in the St Elias Mountains region (Arendt and others, 2008). The study used aircraft laser-altimeter center-line elevation measurements from 17 glaciers in the St Elias Mountains of Alaska and northwestern Canada. The glaciers sampled have a total area of $32900 \mathrm{~km}^{2}$, about $40 \%$ of the area of all the glaciers in the GoA study region. The mass balance for the period September 2003-August 2007 was estimated from the altimetry using regional extrapolation methods along with seasonal corrections and error analysis. The balance for the concurrent period was computed from the hi-res mascon solutions containing St Elias glacier area, namely mascons 6, 7 and 10. Each of these mascons contains glacier area other than that from the St Elias region; therefore, the mascon solutions were scaled by the ratio of St Elias glacier area to the area of all other ice contained within each mascon. A mass balance of $-21.2 \pm 3.7 \mathrm{Gt} \mathrm{a}^{-1}$ is obtained from the laser altimetry while a mass balance of $-20.6 \pm 3.0 \mathrm{Gt} \mathrm{a}^{-1}$ is determined from our GRACE hi-res mascon solutions. The results are in good agreement within their noted errors and demonstrate the validity of the hi-res mascon solutions to accurately determine the mass balance of regional glacier systems having large mass-change signals. The differences are likely from mascon subsampling uncertainties and the uncertainty in the near-surface density used in the altimetry analysis.

\section{Mascon glacier mass-balance amplitudes}

Temporal variations in the GoA mascon solutions result primarily from seasonal variations in snow accumulation and snow/ice wastage (including calving). We interpret the mascon amplitudes as glacier mass-balance amplitudes (Meier, 1984), but we note that there are several factors complicating this interpretation. The first is that the flow of glacier ice redistributes mass throughout the solution domain, potentially resulting in a transfer of ice between adjacent mascons. The second is that some glacier meltwater may reside in subglacial or terrestrial systems and not be measured by GRACE as a mass loss signal. We also note that, although our forward model of terrestrial water storage accounts for snow depth on non-glacier terrain, it likely does not capture all the variability in actual snow accumulation because of the scarcity of climate stations in these regions. Therefore, some of the amplitudes likely contain information on the accumulation and ablation of snow on non-glacier terrain.

The hi-res mascon time series (Fig. 3) illustrate the effects of continentality on mass-balance amplitudes. The largest annual amplitudes are found in the southeast coastal glacier mascons 7, 10, 11 and 12, representing the St Elias, Yakutat and the Glacier Bay, Juneau and Stikine Icefield regions. This is consistent with the high rates of accumulation and large annual ablation found in these maritime glacier regions (Larsen and others, 2007). These regions show the largest reduction in mass loss during the period April 2006-March 2007 , in part likely due to the anomalously large mass input from snowfall in these regions during that period (Fig. 5). 


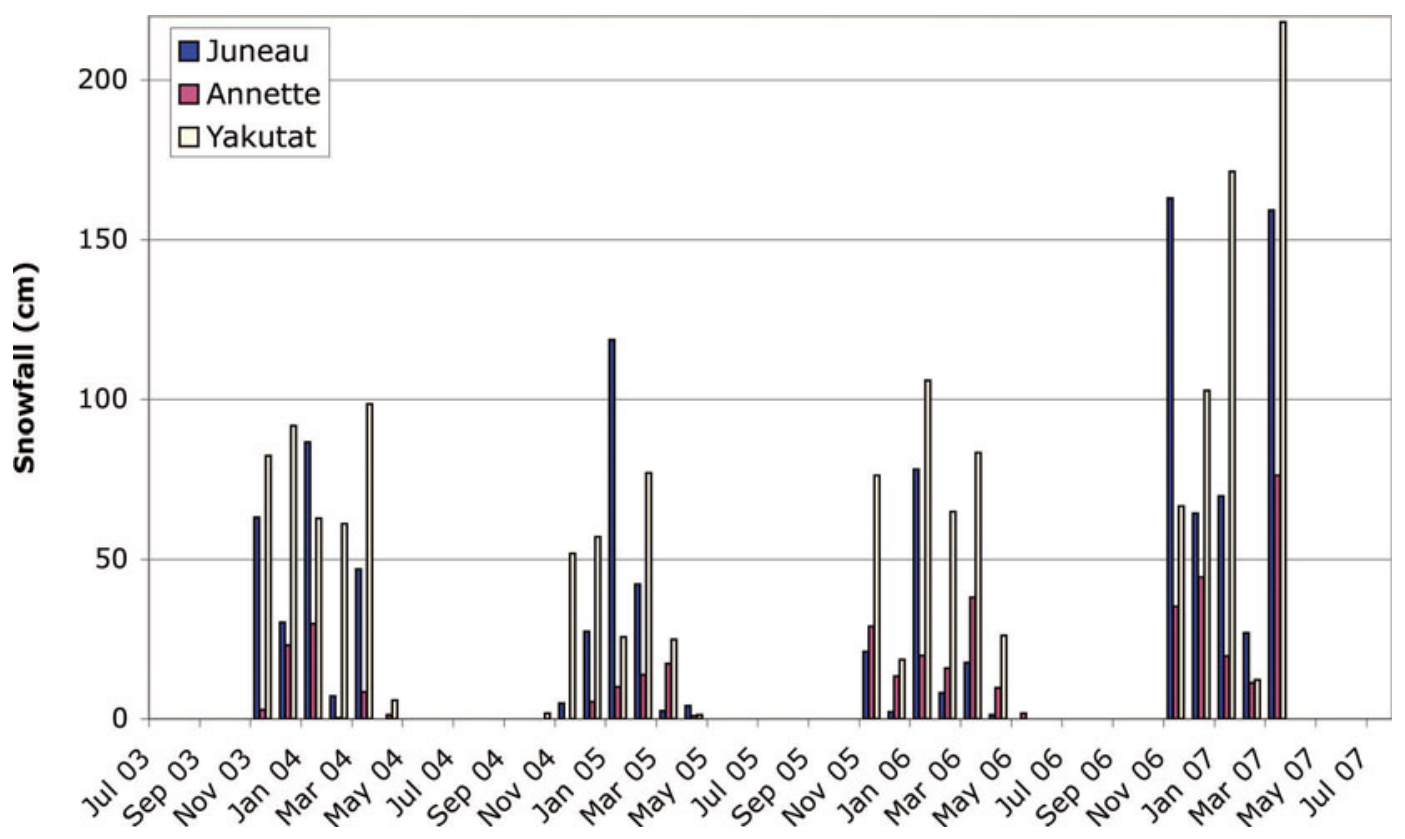

Fig. 5. Snowfall at three GoA sites during the GRACE mascon solution period. Data from http://climate.gi.alaska.edu/Climate/Location/ TimeSeries/index.html

The lowest amplitudes were observed in the Alaska Range (mascons 1-3). Our results support the assumption that maritime glaciers have larger rates of mass turnover and a larger sensitivity to climate (Meier, 1984; Oerlemans and Fortuin, 1992).

Annual amplitudes in mascon 12 were about double those in mascon 7. However, over our study period, the average annual snowfall at Yakutat weather station in mascon 7 $(340 \mathrm{~cm})$ is greater than the average annual snowfall at Juneau weather station in mascon $12(235 \mathrm{~cm}$ ) (see also Fig. 5). This suggests that factors other than snow accumulation control the magnitude of GRACE amplitudes. We speculate that because mascon 7 has about four times more ice cover than mascon 12, there is a substantial component of winter runoff that offsets the mass gains occurring through snow accumulation. The runoff is continually released from englacial or subglacial storage, and progresses in the winter even in the absence of surface melting. During the summer season, the vast accumulation areas in mascon 7 likely collect summer snowfall and offset mass losses due to ablation. Both of these factors probably combine to dampen the mascon 7 amplitudes relative to what they would be in the absence of glacier ice. Further investigations will be necessary to verify these preliminary explanations.

Summer melt-season mass losses start between 31 March and 20 May, while winter accumulation-season mass gains start between 10 September and 20 October. Table 2 contains mass-balance estimates derived from the total glacier mascon time series in Figure 2. The largest summer and annual negative mass balance observed in the total glacier mascon solution occurred during the balance year 2004 . The 2004 summer and annual net balance is $123 \%$ and $178 \%$ more negative than the 4 year average (balance years 2004-07). This corresponds well with the 2004 record summer heatwave in Alaska, which was reflected in record negative balances of Gulkana and Black Rapids Glaciers as observed from in situ mass-balance records (Truffer and others, 2005). Mascon solutions 7, 10 and 11, representing the St Elias, Yakutat and the Glacier Bay and Juneau Icefield regions, exhibit the largest negative summer net balance in response to the summer heatwave of 2004.

A mass-balance modeling study has shown that temporal variations in the hi-res mascon solution from the St Elias Mountains can be reproduced from time variations in temperature and precipitation at nearby weather stations (Arendt and others, in press). Two different models were tuned to the mascon time series using correction factors for temperature and precipitation lapse rates, and accounted for $52-60 \%$ of the variance in the mascon solution. The ability of both models to reproduce the timing of melt- and accumulation-season events, in the absence of phase adjustments in the model optimization routine, suggests climate variations directly (through surface mass balance) or indirectly (through ice-dynamic cycles linked to seasonal climate events) drive the mass-balance variations in this region.

\section{CONCLUSIONS}

Through the application of unique processing techniques and a hi-res mascon parameterization, we have estimated mass variation in the GoA glacier region at 10 day temporal and $49000 \mathrm{~km}^{2}$ spatial sampling. The solutions were obtained over the April 2003-September 2007 period. The hi-res mascon solutions are estimated from a direct reduction of the GRACE KBRR data and do not appear to suffer from contamination ('leakage') from mass change occurring outside the region.

The time series for each of the GoA glacier mascons exhibit significant temporal and spatial mass variability. We have quantified the mass balance and annual amplitudes for each of the GoA glacier mascon regions. The largest negative mass balances were found to be in the Yakutat, Glacier Bay and St Elias mascon regions, while the largest annual amplitudes were found in the Juneau and Stikine mascon regions. These observations are consistent with recent airborne laser-altimeter and SRTM-based studies (Arendt and 
others, 2002, 2006; Larsen and others, 2007). The GoA glacier hi-res mascon solutions also exhibit anomalously large summer 2004 and overall balance year 2004 negative net mass balances representing a $123 \%$ and $178 \%$ increase in loss over the 4 year average. These observations are consistent with the Alaska heatwave of 2004 (Truffer and others, 2005). Additionally, the glacier mascon solutions show the impact of notably large snowfalls, particularly in the southeast, during the 2007 winter balance period (early fall 2006 through early spring 2007). The mass balance of the GoA glacier region over the period April 2003-March 2007 was found to be $-84 \pm 5 \mathrm{Gta}^{-1}$, contributing $0.23 \mathrm{mma}^{-1}$ of GSLR. The mass balance over the period April 2003-March 2006 is $-102 \pm 5 \mathrm{Gta}^{-1}$, which includes the heatwave of 2004 and does not include the large 2007 winter balanceyear snowfall. The large seasonal and interannual variability observed can greatly impact net balance rates when using data over short periods or of limited temporal sampling. Two companion studies were discussed that validate the hi-res mascon solutions of the St Elias glacier region using airborne laser altimetry and surface mass-balance modeling (Arendt and others, 2008, in press).

The hi-res mascon solutions presented here represent an important advancement in resolving surface mass variation from satellite gravity measurements. The results demonstrate that it is possible to recover surface mass variation with an uncertainty of $3.5 \mathrm{Gt}$ (see Table 1) at 10 day temporal and $49000 \mathrm{~km}^{2}$ spatial sampling, with a solution $1 \sigma$ formal uncertainty in the 4 year trends on the order of $1 \mathrm{Gta}^{-1}$. In order to better quantify the contribution of land ice to GSLR, the hi-res mascon approach can be applied to other glacier systems that are exhibiting rapid rates of loss. For example, the Patagonia icefields of Chile and Argentina cover a $17200 \mathrm{~km}^{2}$ area and are estimated to be losing ice mass at a rate of $38 \pm 4 \mathrm{Gta}^{-1}$ (Rignot and others, 2003) and $28 \pm$ $11 \mathrm{Gta}^{-1}$ (Chen and others, 2007). Although the glaciated area of the Patagonia icefields is $54 \%$ of our St Elias validation region, the ice-loss signal is 1.8 times larger (Rignot and others, 2003) and should be resolved by our hires mascon technique. Furthermore, the technique can be applied to both Greenland and Antarctica in order to better quantify the spatial and temporal variation of the ice sheets. The direct measurement of ice-mass variation and the improvements in resolution made possible by the hi-res mascon technique provide important observations to further our knowledge of the world's ice evolution, improve our modeling capability and ultimately improve our ability to predict future changes of ice in response to climate and dynamic forcing

\section{ACKNOWLEDGEMENTS}

Support for this work was provided by NASA under the GRACE Science Team, Interdisciplinary Science (IDS) and Cryospheric Sciences programs. We gratefully acknowledge the quality of the level-1B products produced by our colleagues at the Jet Propulsion Laboratory. We especially thank J.P. Boy and R. Ray for their contributions to the forward models used in this study. We thank T. Williams and D. Pavlis for their many contributions to software and analysis tools development. We gratefully acknowledge W. Abdalati for many technical discussions and support. Finally we thank E. Ivins and R. Motyka for thoughtful reviews that clearly improved the manuscript.

\section{REFERENCES}

Alley, R.B., P.U. Clark, P. Huybrechts and I. Joughin. 2005. Icesheet and sea-level changes. Science, 310(5747), 456-460.

Arendt, A.A., K.A. Echelmeyer, W.D. Harrison, C.S. Lingle and V.B. Valentine. 2002. Rapid wastage of Alaska glaciers and their contribution to rising sea level. Science, 297(5580), 382-386.

Arendt, A. and 7 others. 2006. Updated estimates of glacier volume changes in the western Chugach Mountains, Alaska, and a comparison of regional extrapolation methods. J. Geophys. Res., 111(F3), F03019. (10.1029/2005JF000436.)

Arendt, A., S. Luthcke, C. Larsen, W. Abdalati, W. Krabill and M. Beedle. 2008. Validation of high-resolution GRACE mascon estimates of glacier mass changes in the St Elias Mountains, Alaska, USA, using aircraft laser altimetry. J. Glaciol., 54(188), 778-787.

Arendt, A.A., S. Luthcke and R. Hock. In press. Glacier changes in Alaska: can mass-balance models explain GRACE mascon trends? Ann. Glaciol., 50.

Carre, L. and F. Lyard. 2003. Modeling the barotropic response of the global ocean to atmospheric wind and pressure forcing comparisons with observations. Geophys. Res. Lett., 30(6), 1275. (10.1029/2002GL016473.)

Cazenave, A. 2006. How fast are the ice sheets melting? Science, 314(5803), 1250-1252.

Chao B.F. and A. Au. 1991. Temporal variation of the Earth's lowdegree field caused by atmospheric mass redistribution - 19801988. J. Geophys. Res, 96(B4), 6569-6575.

Chao, B.F., W.P. O'Connor, A.T.C. Chang, D.K. Hall and J.L. Foster. 1987. Snow load effect on the Earth's rotation and gravitational field, 1979-1985. J. Geophys. Res., 92(B9), 9415-9422.

Chen, J.L., B.D. Tapley and C.R. Wilson. 2006. Alaskan mountain glacial melting observed by satellite gravimetry. Earth Planet. Sci. Lett., 248(1-2), 368-378.

Chen, J.L., C.R. Wilson, B.D. Tapley, D.D. Blankenship and E.R. Ivins. 2007. Patagonia Icefield melting observed by Gravity Recovery and Climate Experiment (GRACE). Geophys. Res. Lett., 43(22), L22501. (10.1029/2007GL031871.)

Dyurgerov, M. and G.J. McCabe. 2006. Associations between accelerated glacier mass wastage and increased summer temperature in coastal regions. Arct. Antarct. Alp. Res., 38(2), 190-197.

Echelmeyer, K.A. and 8 others. 1996. Airborne surface profiling of glaciers: a case-study in Alaska. J. Glaciol., 42(142), 538-547.

Ek, M.B. and 7 others. 2003. Implementation of Noah land surface model advances in the National Centers for Environmental Prediction operational mesoscale Eta model. J. Geophys. Res., 108(D22), 8851. (10.1029/2002JD003296.)

Gaposchkin, E.M. 2000. Geoid recovery using geophysical inverse theory applied to satellite to satellite tracking data. NASA Contract Rep. NAS5-99123.

Hofmann-Wellenhof, B. and H. Moritz. 2005. Physical geodesy. Vienna, Springer-Verlag.

Horwath, M. and R. Dietrich. 2006. Errors of regional mass variations inferred from GRACE monthly solutions. Geophys. Res. Lett., 33(7), L07502. (10.1029/2005GL025550.)

Kahn, W.D., S.M. Klosko and W.T. Wells. 1982. Mean gravity anomalies from a combination of Apollo/ATS 6 and GEOS 3/ATS 6 SST tracking campaigns. J. Geophys. Res., 87(B4), 2904-2918.

Larsen, C.F., R.J. Motyka, J.T. Freymueller, K.A. Echelmeyer and E.R. Ivins. 2005. Rapid viscoelastic uplift in southeast Alaska caused by post-Little Ice Age glacial retreats. Earth Planet. Sci. Lett., 237(3-4), 548-560.

Larsen, C.F., R.J. Motyka, A.A. Arendt, K.A. Echelmeyer and P.E. Geissler. 2007. Glacier changes in southeast Alaska and northwest British Columbia and contribution to sea level rise. J. Geophys. Res., 112(F1), F01007. (10.1029/2006JF000586.)

Lee, J. and R. Lund. 2004. Revisiting simple linear regression with autocorrelated errors. Biometrika, 91(1), 240-245. 
Luthcke, S.B., N.P. Zelensky, D.D. Rowlands, F.G. Lemoine and T.A. Williams. 2003. The 1-centimeter orbit: Jason-1 precision orbit determination using GPS, SLR, DORIS, and altimeter data. Mar. Geod., 26(3-4), 399-421.

Luthcke, S.B., D.D. Rowlands, F.G. Lemoine, S.M. Klosko, D. Chinn and J.J. McCarthy. 2006a. Monthly spherical harmonic gravity field solutions determined from GRACE inter-satellite range-rate data alone. Geophys. Res. Lett., 33(2), L02402. (10.1029/ 2005GL024846.)

Luthcke, S.B. and 8 others. 2006b. Recent Greenland ice mass loss by drainage system from satellite gravity observations. Science, 314(5803), 1286-1289.

Meehl, G.A. and 12 others. 2007. Global climate projections. In Solomon, S. and 7 others, eds. Climate change 2007: the physical science basis. Contribution of Working Group I to the Fourth Assessment Report of the Intergovernmental Panel on Climate Change. Cambridge, etc., Cambridge University Press.

Meier, M.F. 1984. Contribution of small glaciers to global sea level. Science, 226(4681), 1418-1421.

Meier, M.F. and A. Post. 1987. Fast tidewater glaciers. J. Geophys. Res., 92(B9), 9051-9058.

Meier, M.F. and 7 others. 2007. Glaciers dominate eustatic sealevel rise in the 21st century. Science, 317(5841), 1064-1067.

Muller, P.M. and W.L. Sjogren. 1968. Mascons: lunar mass concentrations. Science, 161(3842), 680-684.

Oerlemans, J. and J.P.F. Fortuin 1992. Sensitivity of glaciers and small ice caps to greenhouse warming. Science, 258(5079), 115-117.

O'Neel, S., W.T. Pfeffer, R. Krimmel and M. Meier. 2005. Evolving force balance at Columbia Glacier, Alaska, during its rapid retreat. J. Geophys. Res., 110(F3), F03012. (10.1029/ 2005JF000292.)

Peltier, W.R. 2004. Global glacial isostatic adjustment and the surface of the ice-age Earth: the ICE-5G(VM2) model and GRACE. Annu. Rev. Earth Planet. Sci., 32, 111-149.

Petrov, L. and J.-P. Boy. 2004. Study of the atmospheric pressure loading signal in very long baseline interferometry observations. J. Geophys. Res., 109(B3), B03405. (10.1029/2003JB002500.)

Rangelova, E. and M.G. Sideris. In press. Contributions of terrestrial and GRACE data to the study of the secular geoid changes in North America. J. Geodyn.
Raup, B.H., H.H. Kieffer, T.M. Hare and J.S. Kargel. 2000. Generation of data acquisition requests for the ASTER satellite instrument for monitoring a globally distributed target. IEEE Trans. Geosci. Remote Sens., 38(2), 1105-1112.

Ray, R.D. 1999. A global ocean tide model from TOPEX/Poseidon altimetry/GOT99.2. NASA Tech. Mem. 209478.

Ray, R.D. and R.M. Ponte. 2003. Barometric tides from ECMWF operational analyses. Ann. Geophys., 21(8), 1897-1910.

Rignot, E., A. Rivera and G. Casassa. 2003. Contribution of the Patagonian icefields of South America to sea level rise. Science, 302(5644), 434-437.

Rodell, M. and 13 others. 2004. The global land data assimilation system. Bull. Am. Meteorol. Soc., 85(3), 381-394.

Rowlands, D.D., R.D. Ray, D.S. Chinn and F.G. Lemoine. 2002. Short-arc analysis of intersatellite tracking data in a gravity mapping mission. J. Geod., 76(6-7), 307-316.

Rowlands, D.D. and 7 others. 2005. Resolving mass flux at high spatial and temporal resolution using GRACE intersatellite measurements. Geophys. Res. Lett., 32(4), L04310. (10.1029/ 2004GL021908.)

Rummel, R. 1980. Geoid heights, geoid height differences, and mean gravity anomalies from 'low-low' satellite-to-satellite tracking: an error analysis. Columbus, $\mathrm{OH}$, The Ohio State University. Department of Geodetic Science. (Report No. 306.)

Swenson, S. and J. Wahr. 2002. Methods for inferring regional surface-mass anomalies from Gravity Recovery and Climate Experiment (GRACE) measurements of time-variable gravity. J. Geophys. Res., 107(B9), 2193. (10.1029/2001JB000576.)

Tamisiea, M.E., E.W. Leuliette, J.L. Davis and J.X. Mitrovica. 2005. Constraining hydrological and cryospheric mass flux in southeastern Alaska using space-based gravity measurements. Geophys. Res. Lett., 32(20), L20501. (10.1029/2005GL023961.)

Tapley, B.D., S. Bettadpur, J.C. Ries, P.F. Thompson and M.M. Watkins. 2004. GRACE measurements of mass variability in the earth system. Science, 305(5683), 503-505.

Truffer, M., W.D. Harrison and R.S. March. 2005. Correspondence. Record negative glacier balances and low velocities during the 2004 heatwave in Alaska, USA: implications for the interpretation of observations by Zwally and others in Greenland. J. Glaciol., 51(175), 663-664. 